\title{
Comparison of the Phase Transitions of High-pressure Phases of Ammonium Fluoride and Ice at Ambient Pressure
}

Accepted Manuscript: This article has been accepted for publication and undergone full peer review but has not been through the copyediting, typesetting, pagination, and proofreading process, which may lead to differences between this version and the Version of Record.

Cite as: J. Chem. Phys. (in press) (2021); https://doi.org/10.1063/5.0077419

Submitted: 02 November 2021 • Accepted: 07 December 2021 • Accepted Manuscript Online: 07 December 2021

Zainab Sharif and (D) Christoph G. Salzmann

\section{ARTICLES YOU MAY BE INTERESTED IN}

Effect of ammonium fluoride doping on the ice III to ice IX phase transition

The Journal of Chemical Physics 154, 114502 (2021); https://doi.org/10.1063/5.0032485

Detailed crystallographic analysis of the ice V to ice XIII hydrogen-ordering phase transition The Journal of Chemical Physics 154, 134504 (2021); https://doi.org/10.1063/5.0045443

Advances in the experimental exploration of water's phase diagram

The Journal of Chemical Physics 150, 060901 (2019); https://doi.org/10.1063/1.5085163

Challenge us.

What are your needs for periodic signal detection?

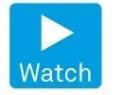

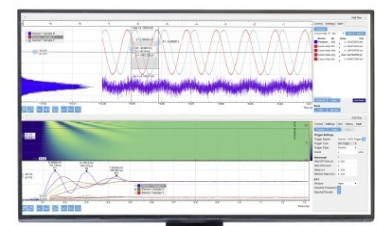

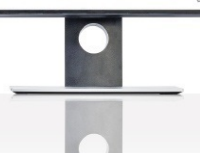

- Zurich - Instruments 
1 Comparison of the Phase Transitions of High-

2 pressure Phases of Ammonium Fluoride and Ice

5 Department of Chemistry, University College London, 20 Gordon Street, London WC1H OAJ,

$6 \quad$ United Kingdom

7 email: c.salzmann@ucl.ac.uk

8 


\section{ABSTRACT}

The phase diagrams of water and ammonium fluoride $\left(\mathrm{NH}_{4} \mathrm{~F}\right)$ display some interesting parallels. Several of the crystalline $\mathrm{NH}_{4} \mathrm{~F}$ phases have isostructural ice counterparts and one of the famous anomalies of water, the fact that the liquid is denser than ice $\mathrm{I} h$, is also found for $\mathrm{NH}_{4} \mathrm{~F}$. Here we investigate the phase transitions of the pressure-quenched high-pressure phases of $\mathrm{NH}_{4} \mathrm{~F}$ upon heating at ambient pressure with X-ray diffraction and calorimetry, and we compare the results with the corresponding ices. $\mathrm{NH}_{4} \mathrm{~F}$ II transforms to $\mathrm{NH}_{4} \mathrm{~F}$ Isd which is a stacking-disordered variant of the stable hexagonal $\mathrm{NH}_{4} \mathrm{~F}$ I $h$ polymorph. Heating $\mathrm{NH}_{4} \mathrm{~F}$ III gives a complex mixture of $\mathrm{NH}_{4} \mathrm{~F}$ II and $\mathrm{NH}_{4} \mathrm{~F}$ Isd while some $\mathrm{NH}_{4} \mathrm{~F}$ III remains initially. Complete conversion to $\mathrm{NH}_{4} \mathrm{~F}$ Isd is achieved above $\sim 220 \mathrm{~K}$. The $\mathrm{NH}_{4} \mathrm{~F}$ II obtained from $\mathrm{NH}_{4} \mathrm{~F}$ III persists to much higher temperatures compared to the corresponding pressure-quenched $\mathrm{NH}_{4} \mathrm{~F}$ II. Quantification of the stacking disorder in $\mathrm{NH}_{4} \mathrm{~F}$ Isd reveals a more sluggish conversion to $\mathrm{NH}_{4} \mathrm{~F}$ I $h$ for $\mathrm{NH}_{4} \mathrm{~F}$ Isd from $\mathrm{NH}_{4} \mathrm{~F}$ III. In general, the presence of stress and strain in the samples appears to have pronounced effects on the phase transition temperatures. $\mathrm{NH}_{4} \mathrm{~F}$ shows a complete lack of amorphous forms at low temperatures either upon low-temperature compression of $\mathrm{NH}_{4} \mathrm{~F}$ I $h$ or heating $\mathrm{NH}_{4} \mathrm{~F}$ III. The amorphous forms of ice are often used to explain the anomalies of water. It will therefore be interesting to explore if liquid $\mathrm{NH}_{4} \mathrm{~F}$ displays more water-like anomalies despite the apparent lack of amorphous forms at low temperatures. 


\section{INTRODUCTION}

Kathleen Lonsdale was among the first to realise the structural similarities between the ambientpressure phases of ammonium fluoride $\left(\mathrm{NH}_{4} \mathrm{~F}\right)$ and ice, both of which showed diffuse starshaped patterns in their Laue photographs.[1] In fact, the two wurtzite-type materials are difficult to distinguish in X-ray diffraction because of their similar heavy-atom compositions, almost matching lattice constants and shared hexagonal symmetry with $\mathrm{NH}_{4} \mathrm{~F}$ I and ice $\mathrm{I} h$ belonging to space groups $P 6_{3} m c$ and $P 6_{3} / m m c$, respectively.[2, 3] Both $\mathrm{NH}_{4} \mathrm{~F}$ I and ice $\mathrm{I} h$ display decreasing melting temperatures with increasing pressure which means that the liquids of both materials are denser that the corresponding crystalline phases. [4] The famous anomaly of ice floating on water is therefore also found for $\mathrm{NH}_{4} \mathrm{~F}$.

Since $\mathrm{NH}_{4} \mathrm{~F}$ I can contain cubic stacking faults, [5] it has recently been suggested that the stable and fully hexagonal polymorph should be called $\mathrm{NH}_{4} \mathrm{~F}$ I $h$ in analogy with the nomenclature used for ice.[6] The crystal structure of $\mathrm{NH}_{4} \mathrm{~F} \mathrm{I} h$ is shown in Figure 1. It contains puckered layers consisting of six-membered rings of hydrogen-bonded $\mathrm{NH}_{4}{ }^{+}$and $\mathrm{F}^{-}$ions in the chair conformation. Upon stacking these layers, additional six-membered rings in the boat conformation form with the heavy-atom positions of a new layer on top of the preceding one. Since only $\mathrm{NH}_{4}{ }^{+}$can hydrogen bond to $\mathrm{F}^{-}$and vice versa, all ring sizes must be even numbered in $\mathrm{NH}_{4} \mathrm{~F}$. This is an important distinction compared to ice where odd-numbered rings of hydrogen-bonded water molecules are possible (see Fig. 3 in ref. [7]). Furthermore, ice can display orientational disorder of the hydrogen-bonded water molecules which gives rise to hydrogen-ordering phase transitions as the molecular orientations become defined at low temperatures.[8] An analogous phenomenon cannot be found for $\mathrm{NH}_{4} \mathrm{~F}$. 
(a)

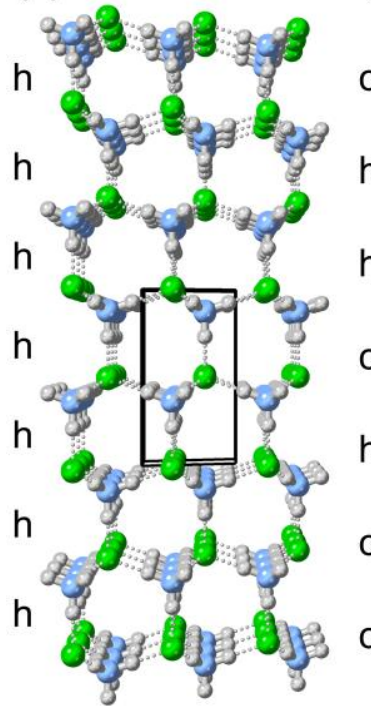

$\mathrm{NH}_{4} \mathrm{~F}$ Ih (b)

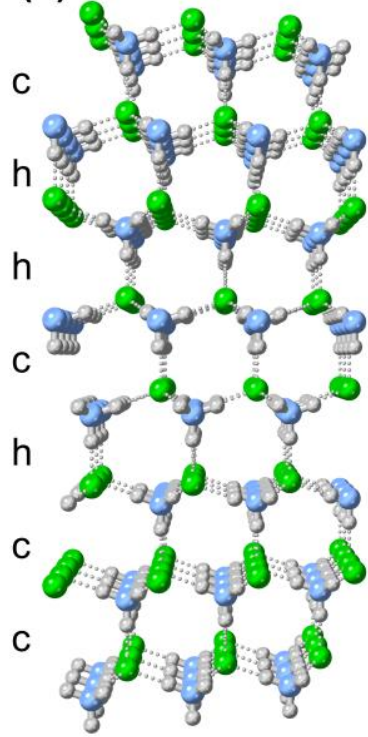

$\mathrm{NH}_{4} \mathrm{~F}$ Isd (c)

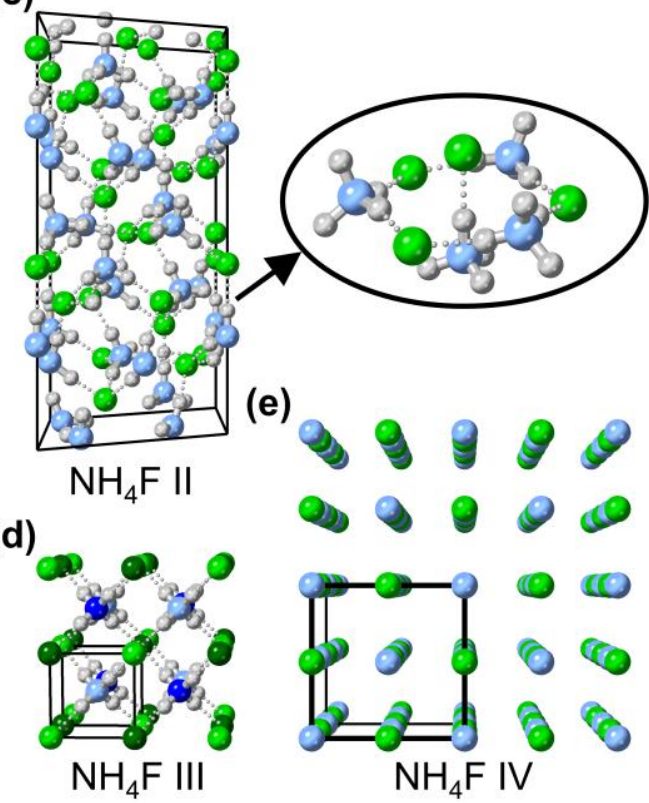

Figure 1: Crystal structures of (a) $\mathrm{NH}_{4} \mathrm{~F}$ Ih, (b) $\mathrm{NH}_{4} \mathrm{~F} \mathrm{Isd,} \mathrm{(c)} \mathrm{NH}_{4} \mathrm{~F} \mathrm{II}$, (d) $\mathrm{NH}_{4} \mathrm{~F}$ III and (e) $\mathrm{NH}_{4} \mathrm{~F}$ IV.[2, 5, 6, 9, 10] Fluorine, nitrogen and hydrogen atoms are indicated by green, blue and grey spheres, respectively. Covalent $N-H$ bonds are shown as solid grey cylinders and $F \cdots H$ hydrogen bonds as dotted lines. For $\mathrm{NH}_{4} \mathrm{~F}$ Ih and Isd, hexagonal and cubic stacking is indicated by ' $h$ ' and 'c'. The interpenetrating $\mathrm{N}-\mathrm{H} \cdots \mathrm{F}$ bond in $\mathrm{NH}_{4} \mathrm{~F}$ II is shown as an inset. The fluorine and nitrogen atoms belonging to different hydrogen-bonded networks in $\mathrm{NH}_{4} \mathrm{~F}$ III are indicated in darker and lighter colours. The unit cells are indicated by black lines.

Structural similarities between $\mathrm{NH}_{4} \mathrm{~F}$ and ice are also found for some of the high-pressure phases. Kuriakose et al. showed that the compression of $\mathrm{NH}_{4} \mathrm{~F}$ I $h$ at ambient temperature to $\sim 0.38 \mathrm{GPa}$ leads to the transformation to $\mathrm{NH}_{4} \mathrm{~F}$ II.[4] Morosin et al. and Wong et al. initially assumed $\mathrm{NH}_{4} \mathrm{~F}$ II to be tetragonal.[11, 12] However, further studies showed that a tetragonal cell was insufficient in describing its structure.[5] Other incorrect assumptions were also drawn on the analogy that $\mathrm{NH}_{4} \mathrm{~F}$ II shared aspects of its phase diagram with the other high pressure ammonium halides which led to it being classified as being cubic.[13-15] Lawson et al. finally determined $\mathrm{NH}_{4} \mathrm{~F}$ II to be rhombohedral with $R 3 c$ space group symmetry. [9] In fact, $\mathrm{NH}_{4} \mathrm{~F}$ II is isostructural with ice IV which is a metastable high-pressure phase of ice.[16] The hallmark 
feature of the crystal structure of $\mathrm{NH}_{4} \mathrm{~F}$ II are hydrogen bonds that thread through six-membered rings as shown in Figure 1.

The phase transition from $\mathrm{NH}_{4} \mathrm{~F}$ I $h$ to $\mathrm{NH}_{4} \mathrm{~F}$ II and ice $\mathrm{I} h$ to ice IV follows a very elegant mechanism first described by Engelhardt and Kamb[17] and now referred to as the EngelhardtKamb-collapse (EKC).[6, 9] This mechanism involves the shifting or rotation of layers followed by 'threading through' of hydrogen bonds through six-membered rings of the layers above and below to two layers above and below. This pulls all layers closer together resulting in an overall density increase of $37 \%$. It has been argued that this mechanism plays an important role in the formation of high-density amorphous ice (HDA) from ice I $h$ at low temperatures.[6] Above $1.0 \mathrm{GPa}$, the cubic $\mathrm{NH}_{4} \mathrm{~F}$ III (space group $P \overline{4} 3 m$ ) forms. It is isostructural with ice VII (space group $P n \overline{3} m$ ) and contains two interpenetrating networks that are not hydrogenbonded to one another as shown in Figure 1.[5] Recently, Bellin et al. showed that the compression of $\mathrm{NH}_{4} \mathrm{~F}$ III beyond $10 \mathrm{GPa}$ yields a tetragonal distortion.[18]

Nabar et al. reported X-ray diffraction data recorded upon heating $\mathrm{NH}_{4} \mathrm{~F}$ II and $\mathrm{NH}_{4} \mathrm{~F}$ III at ambient pressure from $100 \mathrm{~K}$ to room temperature.[5] $\mathrm{NH}_{4} \mathrm{~F}$ II was found to transform to a new phase, $\mathrm{NH}_{4} \mathrm{~F} \mathrm{~V}$, at $\sim 120 \mathrm{~K}$ and to $\mathrm{NH}_{4} \mathrm{~F}$ I $h$ at $\sim 230 \mathrm{~K}$. Upon heating $\mathrm{NH}_{4} \mathrm{~F}$ III, two new phases were observed. $\mathrm{NH}_{4} \mathrm{~F}$ VI formed at $\sim 120 \mathrm{~K}$ which then transformed to $\mathrm{NH}_{4} \mathrm{~F}$ VII at $\sim 200$ K. Phases V and VII were attributed to stacking variants of $\mathrm{NH}_{4} \mathrm{~F} \mathrm{I} h$. The diffraction data in ref. [5] was only reported in terms of the intensity values of the observed reflections and a detailed analysis in terms of the percentages of hexagonal and cubic stacking was not carried out. Regarding $\mathrm{NH}_{4} \mathrm{~F}$ VI, it was concluded that the powder pattern was too complicated to be analysed unambiguously.

The classification of the metastable $\mathrm{NH}_{4} \mathrm{~F}$ V and VII forms as stacking-faulted variants of $\mathrm{NH}_{4} \mathrm{~F}$ I by Nabar et al. preceded that of the corresponding ice I polytypes which are now widely recognised as stacking disordered ice (ice Isd).[19-22] Ice Isd samples are now routinely 
analysed for their cubicities $\left(\Phi_{\mathrm{c}}\right)$ which reflect the percentage of cubic stacking.[20, 23] This is achieved by fitting the diffuse diffraction features that arise from the stacking disorder. Depending on which high-pressure phase of ice is used as a parent material, ice Isd samples with different cubicities are obtained upon heating at ambient pressure.[21, 22, 24] For instance, ice Isd formed by heating ice II yields the highest cubicity of $78 \%$ out of all the high-pressure phases.[8] Ices VII and VIII, which are structurally related to $\mathrm{NH}_{4} \mathrm{~F}$ III, are exceptions with respect to the transformations to ice Isd upon heating at ambient pressure since they form lowdensity amorphous ice (LDA) before the ice Isd.[25-27] Recently, a $\mathrm{NH}_{4} \mathrm{~F}$ II sample was heated to $203 \mathrm{~K}$ which gave a stacking-disordered $\mathrm{NH}_{4} \mathrm{~F}$ sample with a cubicity of $77 \%$.[6] On this basis, it was suggested that the label ' $\mathrm{NH}_{4} \mathrm{~F} \mathrm{~V}$ ' is not needed and that the sample can simply be described as $\mathrm{NH}_{4} \mathrm{~F}$ Isd in analogy with the situation for ice.[6] Figure 1 shows a possible $\mathrm{NH}_{4} \mathrm{~F}$ Isd structure with a stacking sequence of 'cchchhc' where ' $h$ ' and 'c' indicate hexagonal and cubic stacking, respectively. In addition to ice I and $\mathrm{NH}_{4} \mathrm{~F}$, stacking disorder has recently been identified and characterised in a range of structurally related materials including diamond and silver iodide.[28, 29] The stacking disorder in these tetrahedrally-bonded materials is somewhat more complex than the stacking disorder observed in simple close-packed metals.[30] In metals, each stacked layer consists of a flat array of atoms. In the tetrahedrally-bonded materials on the other hand the stacked layer units are 'corrugated' bi-layers. This distinction is important since the mirror operation associated with hexagonal stacking leads to two symmetry-distinct types of layers whereas for metals only one type of layer is needed to describe the stackingdisordered structures.

Finally, $\mathrm{NH}_{4} \mathrm{~F}$ is also known to exist as a plastic phase, $\mathrm{NH}_{4} \mathrm{~F} \mathrm{IV}$, at temperatures above the region of stability of $\mathrm{NH}_{4} \mathrm{~F}$ II.[10] Its crystal structure is thought to be related to the cubic sodium chloride as shown in Figure 1. However, overall, very little is known about this phase of $\mathrm{NH}_{4} \mathrm{~F}$. 
The effect of $\mathrm{NH}_{4} \mathrm{~F}$ doping on the phase diagram of ice has recently been investigated. It was found that the $\mathrm{NH}_{4} \mathrm{~F}$ doping selectively removes the hydrogen-ordered ice II from the phase diagram whereas the neighbouring hydrogen-disordered phases readily incorporate the impurity.[31] It was also shown that $\mathrm{NH}_{4} \mathrm{~F}$ acts as a hydrogen-disordering agent for the hydrogen-ordered ices VIII and IX,[32, 33] and as an inhibitor for the formation of clathrate hydrates.[34, 35]

Most recently, the similarities between ice and $\mathrm{NH}_{4} \mathrm{~F}$ were explored computationally.[36] It was found that $\mathrm{NH}_{4} \mathrm{~F}$ departs from ice-like behaviour above $\sim 80 \mathrm{GPa}$ where close-packed structures emerge. In analogy to the clathrate hydrates, it was suggested that $\mathrm{NH}_{4} \mathrm{~F}$ could be a storage material for small guest molecules such as molecular hydrogen.

Here we investigate the phase transitions of $\mathrm{NH}_{4} \mathrm{~F}$ II and $\mathrm{NH}_{4} \mathrm{~F}$ III upon heating at ambient pressure from 100 to $270 \mathrm{~K}$ using X-ray diffraction and differential scanning calorimetry (DSC). The aims are to clarify the structural nature of the $\mathrm{NH}_{4} \mathrm{~F}$ VI phase and to test if $\mathrm{NH}_{4} \mathrm{~F}$ VII can indeed be described as $\mathrm{NH}_{4} \mathrm{~F}$ Isd. The stacking disorder in $\mathrm{NH}_{4} \mathrm{~F}$ Isd will be characterised as a function of temperature by fitting the diffraction patterns with our MCDIFFaX software. $[22,28]$ The sequence of phase transitions is then compared with those

133 for the structurally related phases of ice. A particularly important point of discussion is the apparent lack of amorphous forms of $\mathrm{NH}_{4} \mathrm{~F}$ since the isostructural ice displays rich polyamorphism with at least two families of amorphous ices.[37]

\section{MATERIALS AND METHODS}

$138 \mathrm{NH}_{4} \mathrm{~F}$ purchased from Sigma Aldrich (catalogue number 216011-100G) with a 98\% trace

139 metals basis purity was ground and stored in a desiccator under vacuum. For the preparation of

$140 \mathrm{NH}_{4} \mathrm{~F}$ II (or $\mathrm{NH}_{4} \mathrm{~F}$ III), $\sim 500 \mathrm{mg}(\sim 100 \mathrm{mg}$ ) of the powder were rapidly transferred into indium 141 cups inside hardened-steel pressure dies and then compressed at $5 \mathrm{kN} \min ^{-1}\left(1 \mathrm{kN} \mathrm{min}{ }^{-1}\right)$ at 
room temperature to $0.6 \mathrm{GPa}(1.75 \mathrm{GPa})$ using a computerised Z100 Zwick Universal Testing Machine. Upon reaching the target pressure, the samples were quenched to $77 \mathrm{~K}$ with liquid nitrogen while keeping the pressure constant. After decompression at $77 \mathrm{~K}$, the samples were recovered from the pressure die under liquid nitrogen and freed from the indium for further analysis. The volume changes of a sample recorded upon room-temperature compression to 1.75 GPa are shown in Figure 2. The $\mathrm{NH}_{4} \mathrm{~F}$ I to $\mathrm{NH}_{4} \mathrm{~F}$ II phase transition takes place in a narrow pressure range whereas the $\mathrm{NH}_{4} \mathrm{~F}$ II to $\mathrm{NH}_{4} \mathrm{~F}$ III transition is more sluggish over a larger pressure range. The respective onset pressures of the phase transitions are 0.418 and $1.317 \mathrm{GPa}$.

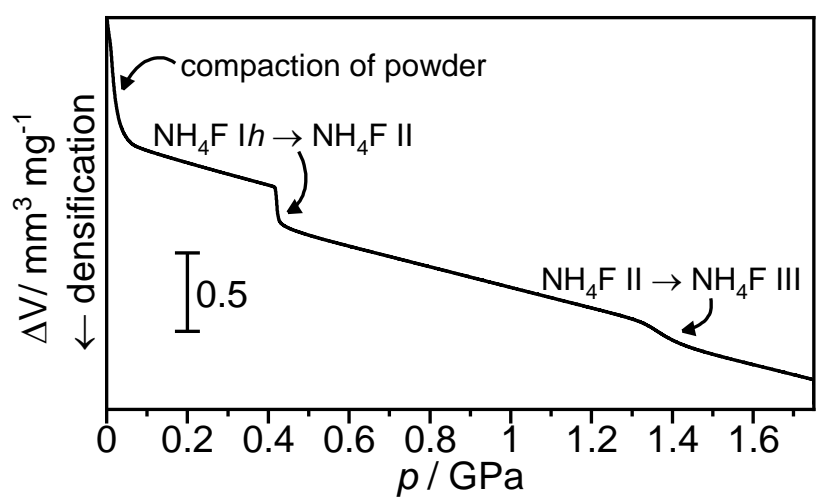

Figure 2: Compression of $102 \mathrm{mg} \mathrm{NH}_{4} \mathrm{~F}$ Ih at room temperature to $1.75 \mathrm{GPa}$ at $1 \mathrm{kN} \mathrm{min}^{-1}$.

\section{Powder X-ray Diffraction (XRD)}

Powders of the recovered $\mathrm{NH}_{4} \mathrm{~F}$ II and $\mathrm{NH}_{4} \mathrm{~F}$ III samples were handled under liquid nitrogen and transferred into a purpose-built Kapton-window sample holder for XRD analysis. Diffraction patterns were recorded starting from $95 \mathrm{~K}$ using a Stoe Stadi P diffractometer with $\mathrm{Cu} \mathrm{K} \alpha 1$ radiation at $40 \mathrm{kV}, 30 \mathrm{~mA}$, a monochromating Ge 111 crystal and Mythen $1 \mathrm{~K}$ linear detector. The cooling of the samples was achieved using an Oxford Instruments CryojetHT. Initial diffraction patterns were recorded at $95 \mathrm{~K}$ followed by heating from $100 \mathrm{~K}$ to $270 \mathrm{~K}$ while collecting diffraction patterns every $10 \mathrm{~K}$ for $\sim 20$ minutes.

\section{Differential Scanning Calorimetry (DSC)}


161 Small pieces of the high-pressure $\mathrm{NH}_{4} \mathrm{~F}$ phases were transferred into stainless-steel DSC pans

162

163

164

165 under liquid nitrogen and quickly transferred into a precooled Perkin Elmer 8000 Advanced Double Furnace differential scanning calorimeter. The samples were heated from $93 \mathrm{~K}$ at $10 \mathrm{~K}$ $\mathrm{min}^{-1}$ to room temperature before cooling back to $93 \mathrm{~K}$ and reheating. The data recorded during the second heating was subtracted from the first heating run as a background subtraction. After the DSC experiments, the pans were weighed with and without $\mathrm{NH}_{4} \mathrm{~F}$ to determine the mass of $\mathrm{NH}_{4} \mathrm{~F}$. The background subtracted data were then divided by the number of moles of $\mathrm{NH}_{4} \mathrm{~F}$ and the heating rate to obtain thermograms with units of $\mathrm{J} \mathrm{mol}^{-1} \mathrm{~K}^{-1}$.

\section{MCDIFFaX analysis}

The XRD patterns were fitted using our MCDIFFaX software.[22, 28] The fitted parameters included the lattice parameters, second-order stacking probabilities, peak profile parameters $(u$, $v, w$, and Gaussian/Lorentzian ratio) and thermal displacement parameters of $\mathrm{N}$ and $\mathrm{F}$. The cubicities were calculated from the second-order stacking probabilities using the equations given in ref. [28].

\section{RESULTS AND DISCUSSION}

Figure 3 shows the $\mathrm{XRD}$ patterns collected upon heating the $\mathrm{NH}_{4} \mathrm{~F}$ II sample at ambient pressure. The initial pattern at $95 \mathrm{~K}$ is consistent with $\mathrm{NH}_{4} \mathrm{~F}$ II.[9] Increasing the temperature to $100 \mathrm{~K}$ leads to an almost complete loss of $\mathrm{NH}_{4} \mathrm{~F}$ II and the appearance of broad diffraction features that are characteristic of $\mathrm{NH}_{4} \mathrm{~F}$ Isd.[6] Fitting the pattern with MCDIFFaX gives a cubicity of $76 \%$ which changes only slightly upon heating to $200 \mathrm{~K}$ where the phase transition to the stable $\mathrm{NH}_{4} \mathrm{~F}$ I $h$ sets in. This sequence of phase transitions seems approximately consistent with the observations of Nabar et al.[5] As mentioned earlier, their $\mathrm{NH}_{4} \mathrm{~F} \mathrm{~V}$ is best described as $\mathrm{NH}_{4} \mathrm{~F}$ Is $d$ which may have contained some $\mathrm{NH}_{4} \mathrm{~F}$ II as can be seen from the positions of the tickmarks shown in Figure 3. Ice IV, the isostructural ice counterpart of $\mathrm{NH}_{4} \mathrm{~F}$ II, transforms to 
185 stacking disordered ice Isd at $\sim 140 \mathrm{~K}$ before the transition to the stable ice $\mathrm{I} h$ at $\sim 240 \mathrm{~K}$ upon

186 heating at ambient pressure.[38] The cubicity of ice Is $d$ made by heating ice IV has not yet been

187 determined.[38]

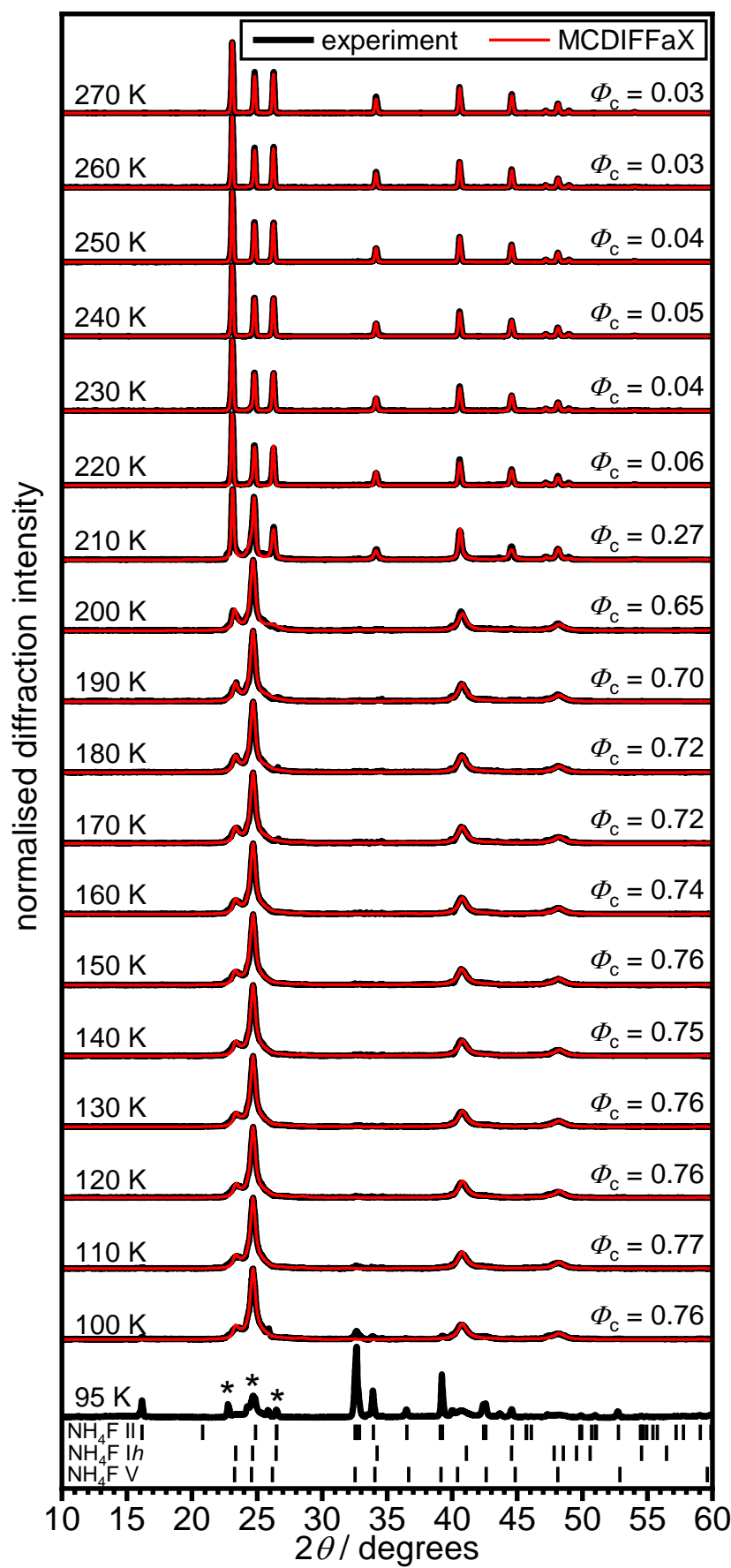

189 Figure 3: Experimental XRD patterns (black lines) and MCDIFFaX fits (red lines) upon heating 
Nabar and co-workers.[5] Asterisks indicate a minor ice Ih impurity that resulted from the sample transfer.

193 Compared to $\mathrm{NH}_{4} \mathrm{~F}$ II, heating $\mathrm{NH}_{4} \mathrm{~F}$ III at ambient pressure gives a more complex sequence of 194 phase transitions as shown in Figure 4. The initial pattern at $95 \mathrm{~K}$ is consistent with $\mathrm{NH}_{4} \mathrm{~F}$ III 195 which displays only a small number of Bragg peaks due to its high space group symmetry. 196 Heating to $100 \mathrm{~K}$ leads to a phase mixture containing $\mathrm{NH}_{4} \mathrm{~F}$ II and $\mathrm{NH}_{4} \mathrm{~F}$ Isd as well as some $197 \mathrm{NH}_{4} \mathrm{~F}$ III that seems to persist. The Bragg peaks of $\mathrm{NH}_{4} \mathrm{~F}$ II are considerably broader than those 198 found for the pressure-quenched sample shown in Figure 3 which means that the domain sizes 199 are smaller for the $\mathrm{NH}_{4} \mathrm{~F}$ II formed by heating $\mathrm{NH}_{4} \mathrm{~F}$ III at ambient pressure. Upon further 200 heating, the amount of $\mathrm{NH}_{4} \mathrm{~F}$ II decreases gradually while more $\mathrm{NH}_{4} \mathrm{~F}$ Isd is formed. Yet, small 201 amounts of $\mathrm{NH}_{4} \mathrm{~F}$ II can still be seen in the patterns up to at least $220 \mathrm{~K}$. This is remarkable 202 considering that the pressure-quenched $\mathrm{NH}_{4} \mathrm{~F}$ II was lost completely upon heating to $110 \mathrm{~K}$ as 203 shown in Figure 3. 


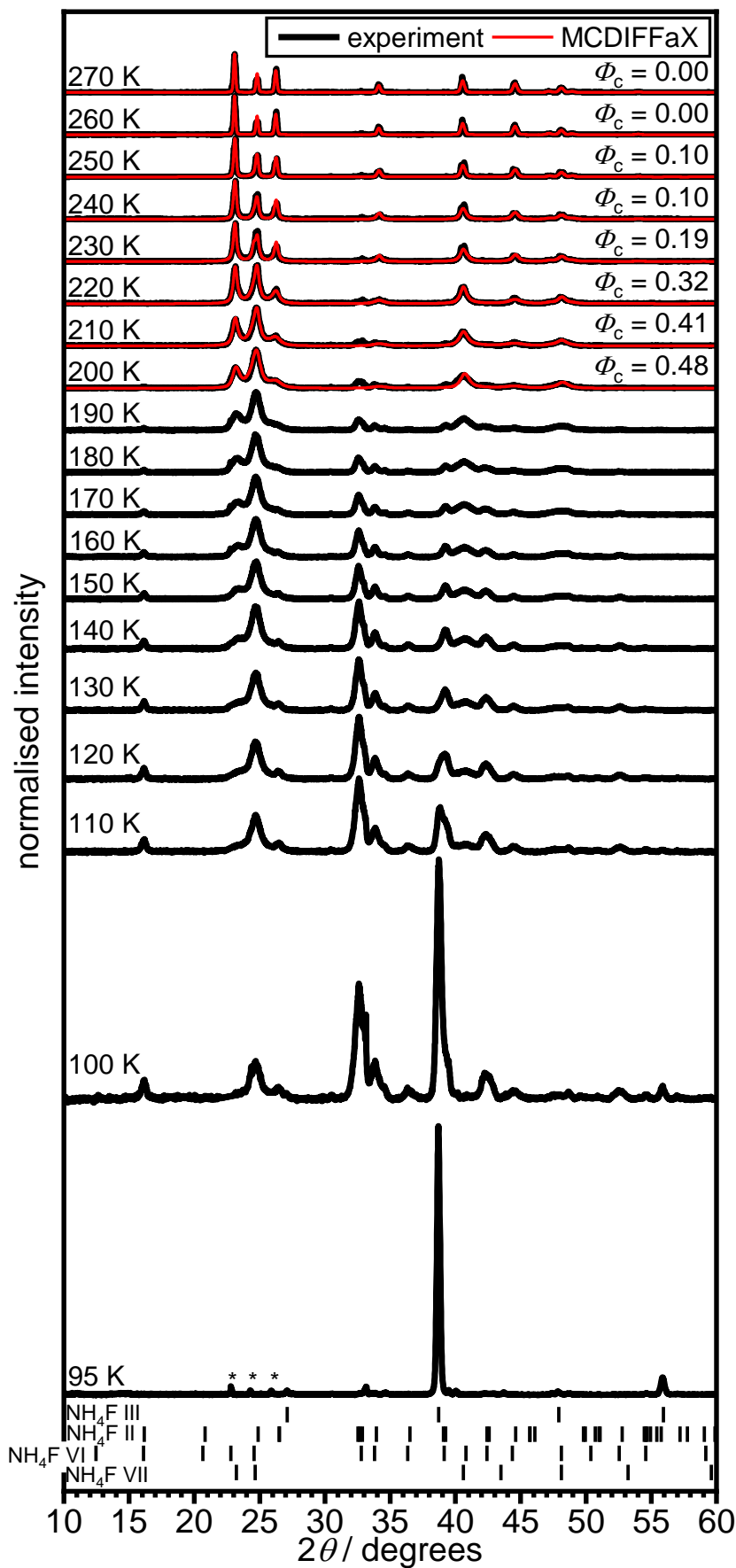

205 Figure 4: XRD patterns (black lines) and MCDIFFaX fits (red lines) upon heating $\mathrm{NH}_{4} \mathrm{~F}$ III at 206 ambient pressure from $95 \mathrm{~K}$ to $270 \mathrm{~K}$. Traces of ice Ih at $95 \mathrm{~K}$ are shown by the asterisks. The 207 tickmarks of $\mathrm{NH}_{4} \mathrm{~F}$ VI and $\mathrm{NH}_{4} \mathrm{~F}$ VII are those reported by Nabar and co-workers. [5] The 208 tickmarks of $\mathrm{NH}_{4} \mathrm{~F}$ III were obtained by reduction of symmetry of a corresponding ice VII cell. 
MCDIFFaX could only be performed from $200 \mathrm{~K}$ onwards, due to the overwhelming presence of additional peaks from other phases.

211 Because of the $\mathrm{NH}_{4} \mathrm{~F}$ II / NH4F Isd phase mixture, it was not possible to analyse the $\mathrm{NH}_{4} \mathrm{~F}$ Isd 212 diffraction data with MCDIFFaX below $200 \mathrm{~K}$. Heating $\mathrm{NH}_{4} \mathrm{~F}$ Isd from $200 \mathrm{~K}$ then leads to a 213 gradual decrease in $\Phi_{\mathrm{c}}$ until pure $\mathrm{NH}_{4} \mathrm{~F} \mathrm{I} h$ is found at $260 \mathrm{~K}$.

Nabar et al. stated that heating of $\mathrm{NH}_{4} \mathrm{~F}$ III led to the formation of a stacking variant $\mathrm{NH}_{4} \mathrm{~F}$ VI at $120 \mathrm{~K}$ which transformed to $\mathrm{NH}_{4} \mathrm{~F}$ VII at $200 \mathrm{~K}$ before turning to $\mathrm{NH}_{4} \mathrm{~F}$ I $h$ at 230 K.[5] On the basis of our data, it can be concluded that their $\mathrm{NH}_{4} \mathrm{~F}$ VI seems to have been a mixture of $\mathrm{NH}_{4} \mathrm{~F}$ II and $\mathrm{NH}_{4} \mathrm{~F}$ Isd which was called $\mathrm{NH}_{4} \mathrm{~F}$ VII once the $\mathrm{NH}_{4} \mathrm{~F}$ II component was lost.[5] Consequently, both $\mathrm{NH}_{4} \mathrm{~F}$ VI and $\mathrm{NH}_{4} \mathrm{~F}$ VII do not seem required to describe the sequence of phase transition observed upon heating $\mathrm{NH}_{4} \mathrm{~F}$ III at ambient pressure.

$\mathrm{NH}_{4} \mathrm{~F}$ III is isostructural with ice VII and its hydrogen-ordered counterpart ice VIII.[8, 32, 39] Heating ices VII and VIII at ambient pressure leads to the formation of LDA at $~ 110$ $\mathrm{K}$, which transforms to ice Isd at $\sim 140 \mathrm{~K}$.[27] Using ultra-fast diffraction, Lin et al. recently observed that upon heating ice VIII, HDA is transiently observed before the LDA.[40] Notably, amorphous phases are not observed upon heating $\mathrm{NH}_{4} \mathrm{~F}$ III. However, judging from the broad Bragg features, both $\mathrm{NH}_{4} \mathrm{~F}$ II and $\mathrm{NH}_{4} \mathrm{~F}$ Isd display quite small domain sizes. The two phases appear in an Ostwald rule-of-stage fashion where $\mathrm{NH}_{4} \mathrm{~F}$ II is more metastable than $\mathrm{NH}_{4} \mathrm{~F}$ Isd.

Figure 5 summarises the cubicities of $\mathrm{NH}_{4} \mathrm{~F}$ Isd obtained upon heating $\mathrm{NH}_{4} \mathrm{~F}$ II and $\mathrm{NH}_{4} \mathrm{~F}$ III. Interestingly, the changes in $\Phi_{\mathrm{c}}$ and therefore the phase transition to $\mathrm{NH}_{4} \mathrm{~F}$ I $h$ are more abrupt for the $\mathrm{NH}_{4} \mathrm{~F}$ Isd obtained from $\mathrm{NH}_{4} \mathrm{~F}$ II. This means that both $\mathrm{NH}_{4} \mathrm{~F}$ II and $\mathrm{NH}_{4} \mathrm{~F}$ I $s d$ from $\mathrm{NH}_{4} \mathrm{~F}$ III display sluggish phase transition kinetics on their way to the stable $\mathrm{NH}_{4} \mathrm{~F} \mathrm{I} h$. 


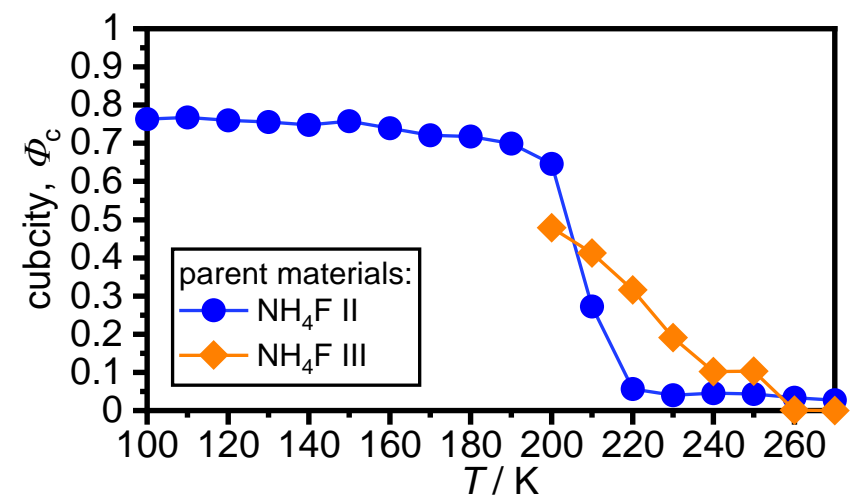

232 Figure 5: Cubicities of $\mathrm{NH}_{4} \mathrm{~F}$ Isd upon heating $\mathrm{NH}_{4} \mathrm{~F}$ II and $\mathrm{NH}_{4} \mathrm{~F}$ III at ambient pressure up to $233270 \mathrm{~K}$. For the $\mathrm{NH}_{4} \mathrm{~F}$ Isd from $\mathrm{NH}_{4} \mathrm{~F}$ III MCDIFFaX fits could only be made from $200 \mathrm{~K}$ onwards due to the presence of $\mathrm{NH}_{4} \mathrm{~F}$ II.

235 The high-pressure phases of $\mathrm{NH}_{4} \mathrm{~F}$ were also characterised with calorimetry at ambient 236 pressure. Figure 6 shows the DSC traces upon heating (1) $\mathrm{NH}_{4} \mathrm{~F}$ II and (2) $\mathrm{NH}_{4} \mathrm{~F}$ III at ambient 237 pressure. In addition to the two pure phases, $\mathrm{NH}_{4} \mathrm{~F}$ I $h$ was cold compressed at $77 \mathrm{~K}$ to $1.4 \mathrm{GPa}$ 238 as described in ref. [6]. According to XRD analysis, this sample consisted of $70 \mathrm{w} \% \mathrm{NH}_{4} \mathrm{~F} \mathrm{II}$ 239 and $30 \mathrm{w} \% \mathrm{NH}_{4} \mathrm{~F}$ I $h$. DSC scan (3) in Figure 6 was obtained by heating this sample.

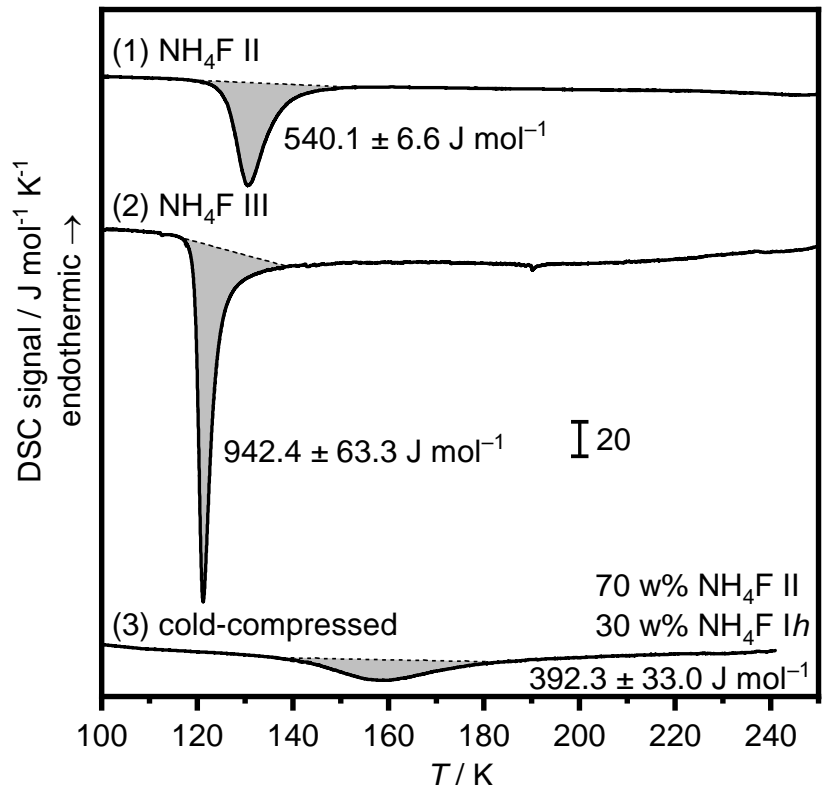

241 Figure 6: DSC scans of (1) $\mathrm{NH}_{4} \mathrm{~F}$ II made by compression to 0.6 GPa at room temperature, (2)

$242 \mathrm{NH}_{4} \mathrm{~F}$ III made by compression to $1.75 \mathrm{GPa}$ at room temperature and (3) $\mathrm{NH}_{4} \mathrm{~F}$ Ih compressed to $243 \quad 1.4 \mathrm{GPa}$ at $77 \mathrm{~K}$ as described in ref. [6] which was found to give $70 \mathrm{w} \% \mathrm{NH}_{4} \mathrm{~F} \mathrm{II}$ and $30 \mathrm{w} \%$ 

dashed lines indicate the baselines used for the integrations of the exotherms.

Pressure-quenched $\mathrm{NH}_{4} \mathrm{~F}$ II transforms to $\mathrm{NH}_{4} \mathrm{~F}$ Isd with an onset temperature of $120 \mathrm{~K}$ and the area of the exotherm resulting from the transition was determined as $-540.1 \pm 6.6 \mathrm{~J} \mathrm{~mol}^{-1}$. The enthalpy of the corresponding phase transition from the isostructural ice IV to ice Isd is $-938 \pm$ $14 \mathrm{~J} \mathrm{~mol}^{-1}$.[38] In analogy to the situation for ice, the phase transition from $\mathrm{NH}_{4} \mathrm{~F}$ Isd to $\mathrm{I} h$ appears to be very weak and is not seen in our DSC data.

The thermogram of $\mathrm{NH}_{4} \mathrm{~F}$ III displays a sharp exotherm with an onset temperature of $116 \mathrm{~K}$ and an area of $-942.4 \pm 63.3 \mathrm{~J} \mathrm{~mol}^{-1}$ corresponding to the phase transition to a mixture of $\mathrm{NH}_{4} \mathrm{~F}$ II and $\mathrm{NH}_{4} \mathrm{~F}$ Isd. The baseline after the exotherm is considerably lower compared to before the phase transition which made the integration of the exotherm somewhat difficult. The lower baseline is consistent with a gradual exothermic transformation from $\mathrm{NH}_{4} \mathrm{~F}$ II to $\mathrm{NH}_{4} \mathrm{~F}$ Isd over an extended temperature range as observed in the XRD analysis in Figure 4. Accordingly, the $-942.4 \mathrm{~J} \mathrm{~mol}^{-1}$ only reflects the heat released during the initial burst of the phase transition and the heat released during the gradual phase transition from $\mathrm{NH}_{4} \mathrm{~F}$ II to $\mathrm{NH}_{4} \mathrm{~F}$ Isd is not captured in the integration. Increasing the upper integration limit to $240 \mathrm{~K}$ gives a 260 heat release of $-2010 \mathrm{~J} \mathrm{~mol}^{-1}$. For comparison, the ice VIII to ice Isd phase transition, which 261 includes an intermediate stage of LDA, has an enthalpy change of $-2667 \pm 25 \mathrm{~J} \mathrm{~mol}^{-1}$.[41, 42] 262 This means that even with this generous integration limits, the phase transition from ice VIII to 263 ice Isd is more exothermic than the corresponding phase transition from $\mathrm{NH}_{4} \mathrm{~F}$ III to $\mathrm{NH}_{4} \mathrm{~F}$ Isd. All observed phase transitions of $\mathrm{NH}_{4} \mathrm{~F}$ were found to be irreversible as demonstrated by cooling $\mathrm{NH}_{4} \mathrm{~F}$ I $h$ to low temperatures and consistent with $\mathrm{NH}_{4} \mathrm{~F}$ I $h$ being the 266 thermodynamically stable phase at ambient pressure. In general, the phase transitions of the $267 \mathrm{NH}_{4} \mathrm{~F}$ high-pressure phases to $\mathrm{NH}_{4} \mathrm{~F}$ Isd seem to be less exothermic than the corresponding 268 phase transitions of ice. These differences could arise from the underlying thermodynamics of 
the two materials. It is interesting to note that $\mathrm{NH}_{4} \mathrm{~F}$ III forms already at $\sim 1.3 \mathrm{GPa}$ upon compression at room temperature (see Figure 2) whereas pressures greater than $\sim 2.2 \mathrm{GPa}$ are needed to form ice VII.[8] Hence, smaller differences in free energy would be expected between

272

$\mathrm{NH}_{4} \mathrm{~F}$ III and $\mathrm{NH}_{4} \mathrm{~F}$ Is $d$ compared to ice VII and ice Isd consistent with our calorimetric data. However, this viewpoint does not take into account that ice VII transforms to its ordered counterpart ice VIII upon cooling which leads to a reduction in free energy at low temperatures. Also, since all investigated phase transitions are irreversible, it is difficult to be sure if the heat releases are only governed by the underlying thermodynamics of the bulk phases. For example, irreversible releases of stress and strain in the samples or surface effects in general may also contribute to the observed enthalpies.

The cold-compressed $\mathrm{NH}_{4} \mathrm{~F}$ I $h$ sample that contains $70 \mathrm{w} \% \mathrm{NH}_{4} \mathrm{~F}$ II and $30 \mathrm{w} \% \mathrm{NH}_{4} \mathrm{~F}$ I $h$ displays an exotherm with an onset temperature of $139 \mathrm{~K}$ and an area of $392.3 \pm 33.0 \mathrm{~J} \mathrm{~mol}^{-}$

1. The area of the exotherm seems meaningful since $70 \%$ of the $540.1 \mathrm{~J} \mathrm{~mol}^{-1}$ obtained upon heating pure $\mathrm{NH}_{4} \mathrm{~F}$ II is $378.1 \mathrm{~J} \mathrm{~mol}^{-1}$ which agrees within error with the heat released upon heating the cold-compressed sample. However, the exotherm of the cold-compressed sample is found at a higher temperature and broader compared to the exotherm of the pure and pressurequenched $\mathrm{NH}_{4} \mathrm{~F}$ II sample. The higher transition temperature is somewhat surprising. Naively, it could have been assumed that the $\mathrm{NH}_{4} \mathrm{~F}$ II domains in the cold-compressed sample should experience more strain and stress, and that this reduces its thermal stability. However, evidently, the opposite is the case.

\section{CONCLUSIONS}

Heating the high-pressure phases $\mathrm{NH}_{4} \mathrm{~F}$ II and $\mathrm{NH}_{4} \mathrm{~F}$ III at ambient pressure has revealed some interesting parallels but also differences compared with the corresponding isostructural ice phases. The pressure-quenched $\mathrm{NH}_{4} \mathrm{~F}$ II transforms to $\mathrm{NH}_{4} \mathrm{~F}$ Isd upon heating in a similar fashion as the isostructural ice analogue ice IV. For pressure-quenched $\mathrm{NH}_{4} \mathrm{~F}$ III, a different 
behaviour is observed compared to the isostructural ice VII/VIII. Instead of transforming to LDA and later ice Isd, heating $\mathrm{NH}_{4} \mathrm{~F}$ III gives a phase mixture of $\mathrm{NH}_{4} \mathrm{~F}$ II and $\mathrm{NH}_{4} \mathrm{~F}$ Isd with some $\mathrm{NH}_{4} \mathrm{~F}$ III persisting initally. This complex phase mixture then transforms gradually to $\mathrm{NH}_{4} \mathrm{~F}$ Isd upon heating. In both cases and consistent with the situation for ice, the stable hexagonal $\mathrm{NH}_{4} \mathrm{~F}$ I $h$ polymorph is found above $260 \mathrm{~K}$. The previously assigned phase labels $\mathrm{NH}_{4} \mathrm{~F} \mathrm{~V}, \mathrm{NH}_{4} \mathrm{~F}$ VI and $\mathrm{NH}_{4} \mathrm{~F}$ VII[5] do not seem to be required to describe the sequences of phase transitions observed upon heating $\mathrm{NH}_{4} \mathrm{~F}$ II and $\mathrm{NH}_{4} \mathrm{~F}$ III at ambient pressure.

Depending on how $\mathrm{NH}_{4} \mathrm{~F}$ II is made, it can display very different phase transition properties. The pressure-quenched material, which is highly crystalline according to X-ray diffraction, transforms rapidly at already $\sim 100 \mathrm{~K}$. The $\mathrm{NH}_{4} \mathrm{~F}$ II obtained from $\mathrm{NH}_{4} \mathrm{~F}$ III at ambient pressure on the other hand displays broad Bragg peaks indicating small domain sizes. Remarkably, small amounts of this $\mathrm{NH}_{4} \mathrm{~F}$ II persist up to $\sim 230 \mathrm{~K}$ while it undergoes a gradual phase transition to $\mathrm{NH}_{4} \mathrm{~F}$ Isd. A 'delayed' phase transition of $\mathrm{NH}_{4} \mathrm{~F}$ II to $\mathrm{NH}_{4} \mathrm{~F}$ Isd is also observed for the material cold-compressed at $77 \mathrm{~K}$ which also displays broad X-ray diffraction features (see Figure 1 in ref. [6]). For $\mathrm{NH}_{4} \mathrm{~F}$, it appears that stress and strain in the material are capable of delaying the phase transitions upon heating. A way to rationalise this is that small domains of $\mathrm{NH}_{4} \mathrm{~F}$ II are embedded within matrices of more stable $\mathrm{NH}_{4} \mathrm{~F}$ materials. As the $\mathrm{NH}_{4} \mathrm{~F}$ II transforms to the lower-density $\mathrm{NH}_{4} \mathrm{~F}$ Isd upon heating, the pressure may rise locally which then counteracts and consequently delays the phase transition.

An interesting parallel between $\mathrm{NH}_{4} \mathrm{~F}$ and ice is the metastable stage of the stacking

314 disordered material before the phase transition to the stable hexagonal materials at higher 315 temperatures. In light of the recent discovery of fully cubic ice Ic, [43-45] a question now arises as to whether a fully cubic $\mathrm{NH}_{4} \mathrm{~F}$ I $c$ can be prepared. The highest cubicity obtained by us so far is $76 \%$. The preparation of ice Ic was achieved through heating of ice XVII.[43] The preparation 
contains five-membered rings. This means that a corresponding $\mathrm{NH}_{4} \mathrm{~F}$ structure is unlikely and hence this route to $\mathrm{NH}_{4} \mathrm{~F}$ I $c$ seems difficult. Komatsu et al. prepared ice Ic by evacuation of the $\mathrm{C}_{2}$ hydrogen hydrate.[44] The water network in this clathrate hydrate has the structure of ice Ic with only six-membered rings. A corresponding $\mathrm{NH}_{4} \mathrm{~F}$ material with $\mathrm{H}_{2}$ guest molecules could be a promising starting point for making $\mathrm{NH}_{4} \mathrm{~F}$ I $c$. If $\mathrm{NH}_{4} \mathrm{~F}$ I $c$ can be prepared, it would be interesting to investigate if it transforms directly to its hexagonal counterpart upon heating as seen for ice $[44,46]$ or if the conversion takes place via stacking disordered intermediates.[45] Liquid ammonium fluoride certainly deserves further attention. As mentioned earlier, it is anomalous like water in the sense that it is denser than the low-pressure crystalline phase. In the case of water, the existence of two amorphous forms at low temperature and a possible second critical point are often used to explain its anomalies.[47, 48] It will be interesting to

330 investigate if liquid $\mathrm{NH}_{4} \mathrm{~F}$ displays more water-like anomalies which would be remarkable 331 given the absence of amorphous forms of $\mathrm{NH}_{4} \mathrm{~F}$ at low temperatures.

\section{ACKNOWLEDGMENTS}

333 Funding is acknowledged from the European Research Council under the European Union's 334 Horizon 2020 research and innovation programme (grant agreement No 725271). We thank M.

335 Vickers and J. Cockcroft for access to the Cryojet, and A. Rosu-Finsen and S. Halukeerthi for 336 help with some of the experiments.

\section{DATA AVAILABILITY STATEMENT}

338 All data were collected in our lab and are available from the corresponding author upon 339 reasonable request.

\section{REFERENCES}

341 [1] K. Lonsdale, Nature 158, 582 (1946). 
342 [2] C. G. V. Beek, J. Overeem, J. R. Ruble, and B. M. Craven, Canadian Journal of $343 \quad$ Chemistry 74, 943 (1996).

344 [3] B. Morosin, Acta Crystallographica Section B 26, 1635 (1970).

345 [4] A. K. Kuriakose, and E. Whalley, The Journal of Chemical Physics 48, 2025 (1968).

346 [5] M. A. Nabar, L. D. Calvert, and E. Whalley, The Journal of Chemical Physics 51, 1353 $347 \quad$ (1969).

348 [6] J. J. Shephard, S. Ling, G. C. Sosso, A. Michaelides, B. Slater, and C. G. Salzmann, J. 349 Phys. Chem. Lett. 8, 1645 (2017).

350 [7] C. G. Salzmann, P. G. Radaelli, B. Slater, and J. L. Finney, Physical Chemistry 351

352 [8] C. G. Salzmann, The Journal of Chemical Physics 150, 060901 (2019).

353 [9] A. Lawson, R. Roof, J. Jorgensen, B. Morosin, and J. Schirber, Acta Crystallographica 354 Section B: Structural Science 45, 212 (1989).

355 [10] L. D. Calvert, and E. Whalley, The Journal of Chemical Physics 53, 2151 (1970).

356 [11] B. Morosin, and J. E. Schirber, The Journal of Chemical Physics 42, 1389 (1965).

357 [12] P. T. T. Wong, and E. Whalley, Review of Scientific Instruments 43, 935 (1972).

358 [13] J. Kasahara, I. Ohno, and K. Iida, J. Phys. Earth. 19, 47 (1971).

359 [14] R. Stevenson, The Journal of Chemical Physics 34, 346 (1961).

360 [15] C. A. Swenson, and J. R. Tedeschi, The Journal of Chemical Physics 40, 1141 (1964).

361 [16] H. Engelhardt, and E. Whalley, J. Chem. Phys. 56, 2678 (1972).

362 [17] H. Engelhardt, and B. Kamb, The Journal of Chemical Physics 75, 5887 (1981).

363 [18] C. Bellin, A. Mafety, C. Narayana, P. Giura, G. Rousse, J.-P. Itié, A. Polian, A. M. 364 Saitta, and A. Shukla, Phys. Rev. B 96, 094110 (2017).

365 [19] W. Kuhs, F., D. Bliss, V., and J. Finney, L., J. Phys. Colloques 48, C1 (1987). 
[20] T. L. Malkin, B. J. Murray, A. V. Brukhno, A. J., and C. G. Salzmann, Proc. Natl. Acad. Sci. USA 109, 1041 (2012).

[21] W. F. Kuhs, C. Sippel, A. Falenty, and T. C. Hansen, PNAS 109, 21259 (2012).

[22] T. L. Malkin, B. J. Murray, C. G. Salzmann, V. Molinero, S. J. Pickering, and T. F. Whale, Physical Chemistry Chemical Physics 17, 60 (2015).

[23] T. C. Hansen, M. M. Koza, and W. F. Kuhs, J. Phys.: Condens. Matter 20, 285104 (2008).

[24] H. Y. Playford, T. F. Whale, B. J. Murray, M. G. Tucker, and C. G. Salzmann, J. Appl. Crystal. 51, 1211 (2018).

[25] D. D. Klug, Y. P. Handa, J. S. Tse, and E. Whalley, J. Chem. Phys. 90, 2390 (1989).

[26] S. Klotz, J. M. Besson, G. Hamel, R. J. Nelmes, J. S. Loveday, and W. G. Marshall, Nature 398, 681 (1999).

[27] J. J. Shephard, S. Klotz, M. Vickers, and C. G. Salzmann, J. Chem. Phys. 144, 204502 (2016).

[28] C. G. Salzmann, B. J. Murray, and J. J. Shephard, Diamond and Related Materials 59, 69 (2015).

[29] R. L. Smith, M. Vickers, M. Rosillo-Lopez, and C. G. Salzmann, Crystal Growth \& 383 Design 19, 2131 (2019).

C. H. Loach, and G. J. Ackland, Phys. Rev. Lett. 119, 205701 (2017).

[31] J. J. Shephard, B. Slater, P. Harvey, M. Hart, C. L. Bull, S. T. Bramwell, and C. G.

[32] C. G. Salzmann, Z. Sharif, C. L. Bull, S. T. Bramwell, A. Rosu-Finsen, and N. P. 388 Funnell, J. Phys. Chem. C 123, 16486 (2019).

[33] Z. Sharif, J. J. Shephard, B. Slater, C. L. Bull, M. Hart, and C. G. Salzmann, J. Chem. 
[34] K. Shin, I. L. Moudrakovski, M. D. Davari, S. Alavi, C. I. Ratcliffe, and J. A. Ripmeester, CrystEngComm 16, 7209 (2014).

[35] S. Park, D. Lim, Y. Seo, and H. Lee, Chem. Comm. 51, 8761 (2015).

[36] L. J. Conway, K. Brown, J. S. Loveday, and A. Hermann, J. Chem. Phys. 154, 204501 (2021).

[37] T. Loerting, K. Winkel, M. Seidl, M. Bauer, C. Mitterdorfer, P. H. Handle, C. G. Salzmann, E. Mayer, J. L. Finney, and D. T. Bowron, Physical Chemistry Chemical Physics 13, 8783 (2011).

[38] C. G. Salzmann, E. Mayer, and A. Hallbrucker, Physical Chemistry Chemical Physics 6, 1269 (2004).

[39] W. F. Kuhs, J. L. Finney, C. Vettier, and D. V. Bliss, The Journal of Chemical Physics 81, $3612(1984)$

[40] C. Lin, X. Liu, X. Yong, J. S. Tse, J. S. Smith, N. J. English, B. Wang, M. Li, W. Yang, and H.-K. Mao, Proceedings of the National Academy of Sciences 117, 15437 (2020).

[41] Y. P. Handa, D. D. Klug, and E. Whalley, Canadian Journal of Chemistry 66, 919 (1988).

[42] S. Klotz, T. Strässle, C. G. Salzmann, J. Philippe, and S. F. Parker, Europhys. Lett. 72, $576(2005)$.

[43] L. del Rosso, M. Celli, F. Grazzi, M. Catti, T. C. Hansen, A. D. Fortes, and L. Ulivi, Nature Materials 2020).

[44] K. Komatsu, S. Machida, F. Noritake, T. Hattori, A. Sano-Furukawa, R. Yamane, K. Yamashita, and H. Kagi, Nature Communications 11, 464 (2020).

[45] C. G. Salzmann, and B. J. Murray, Nature Materials 19, 586 (2020).

[46] L. Del Rosso, M. Celli, and L. Ulivi, Nature Communications 7, 13394 (2016).

[47] P. H. Poole, F. Sciortino, U. Essmann, and H. E. Stanley, Nature 360, 324 (1992). 
[48] P. Gallo, K. Amann-Winkel, C. A. Angell, M. A. Anisimov, F. Caupin, C. Chakravarty, 
(a)

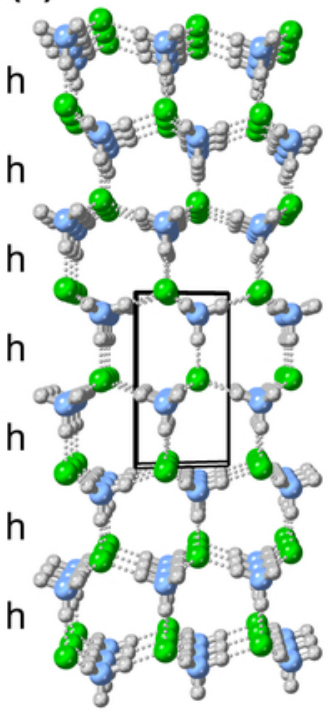

$\mathrm{NH}_{4} \mathrm{~F} \mathrm{Ih}$

(b)

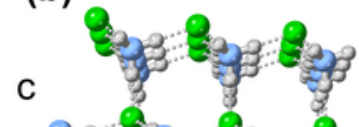

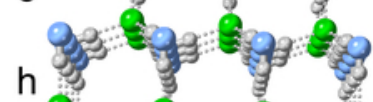

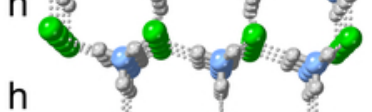

$\mathrm{h}$

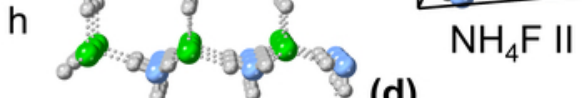

c 2.28 :

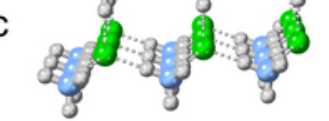

$\mathrm{NH}_{4} \mathrm{~F}$ Isd (d)

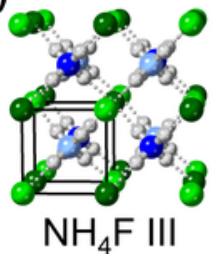

(c)

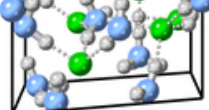

(e)

- 10

a 100

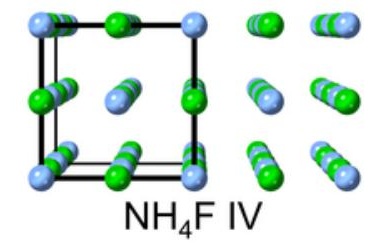

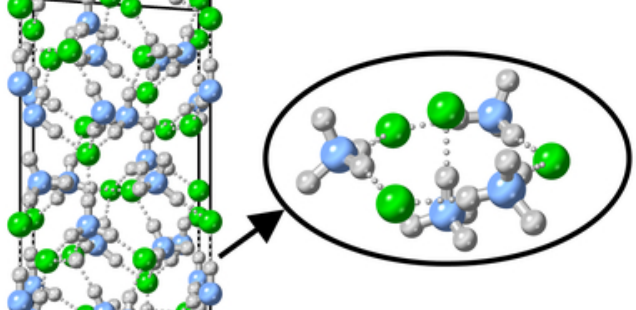




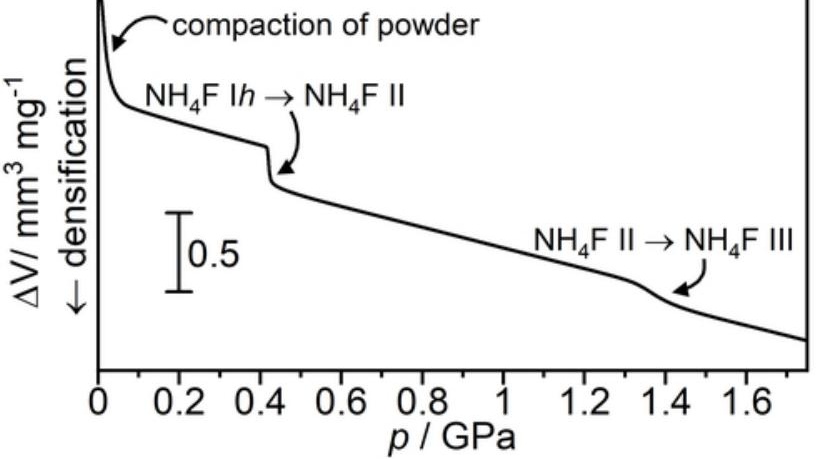






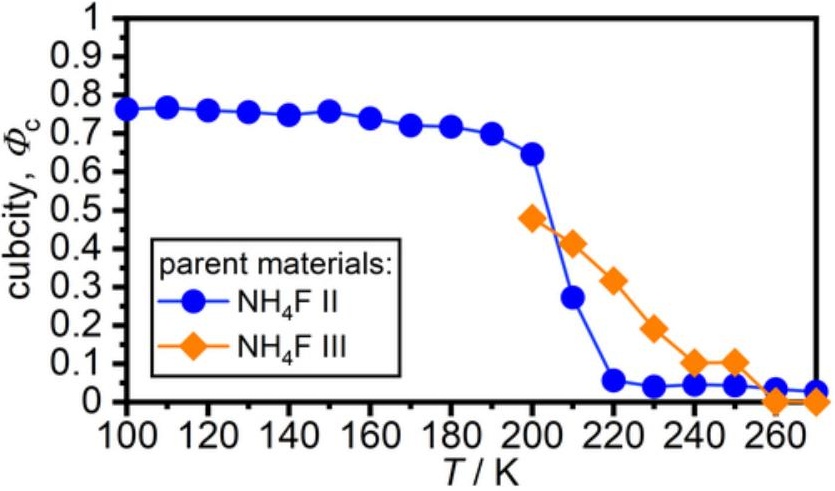


(1) $\mathrm{NH}_{4} \mathrm{~F}$ II

$540.1 \pm 6.6 \mathrm{~J} \mathrm{~mol}^{-1}$

(2) $\mathrm{NH}_{4} \mathrm{~F}$ III

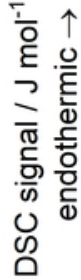

$942.4 \pm 63.3 \mathrm{~J} \mathrm{~mol}^{-1}$

I20

$70 \mathrm{w} \% \mathrm{NH}_{4} \mathrm{~F}$ II

(3) cold-compressed $30 \mathrm{w} \% \mathrm{NH}_{4} \mathrm{~F} \mathrm{Ih}$ $392.3 \pm 33.0 \mathrm{~J} \mathrm{~mol}^{-1}$ 100 120 140 160 200 $220 \quad 240$ 